\title{
Integrando o espaço virtual de aprendizagem “Eva” à formação de professores: estudo de caso sobre o currículo de Física no ensino médio
}

When the teachers' formation is integrating the virtual space of apprenticeship “ Eva “: case study on the curriculum of physics in the secondary education

\author{
Ernesto Macedo Reis ${ }^{1}$ \\ Marília Paixão Linhares ${ }^{2}$
}

Resumo: Este trabalho relata um experimento didático desenvolvido no âmbito de uma proposta de formação inicial de professores de Física. Um ambiente virtual de aprendizagem apóia as aulas presenciais da disciplina curricular denominada Estratégias para o Ensino de Física. O objetivo da proposta de formação é oportunizar que os estudantes exponham suas concepções a cerca do conhecimento profissional, através de atividades que estimulem a reflexão sobre a docência, promovam interatividade e incentivem o trabalho cooperativo. Apresentamos neste artigo os resultados de um dos Estudos de Caso da disciplina: "O Currículo de Física: contexto e reflexões”. Analisamos a evolução das concepções dos licenciandos sobre ensino, conteúdo, metodologia, avaliação e currículo. A eficácia e a funcionalidade do ambiente virtual de aprendizagem também foram avaliadas.

Palavras-chave: formação inicial de professores de Física, ambiente virtual de aprendizagem.

Abstract: This work was developed in the context of initial formation of physics teachers. A virtual learning environment was used as support instrument in the discipline called Strategies for the Physics Teaching. The objective is to give chance to the students to expose their conceptions about professional knowledge, through activities that stimulates the reflection about the professorship, promotes interactivity and stimulates cooperative work. In this study we describe the data relative to the study of case "Physics Curriculum in the High School”. The student's conceptions evolution about teaching, content, methodology, evaluation and curriculum were

\footnotetext{
${ }^{1}$ Centro Federal de Educação Tecnológica de Campos, Campos dos Goytacazes - RJ, ereis@cefetcampos.br

${ }^{2}$ Laboratório de Ciências Física - UENF, Campos dos Goytacazes - RJ, paixaoli@uenf.br
} 
analyzed. The effectiveness and functionality of the virtual learning environment was demonstrated.

Key-words: formation of physics teachers, virtual environment learning.

\section{Introdução}

Este trabalho faz parte de um projeto de pesquisa que tem como foco a formação de professores de Física e a utilização de Tecnologias de Informação e Comunicação (TIC) no ensino de Ciências/Física (Reis, 2008). O recorte do estudo contempla uma ação de formação de professores de Física apoiada por um ambiente virtual de aprendizagem sobre o currículo de Física.

No caso das TIC elas funcionam como parte integrante do cotidiano de nossa sociedade e na formação de professores de Ciências, os ambientes de aprendizagem e a Internet podem auxiliar o professor a superar uma visão unicamente instrumental dos meios tecnológicos. Para Gianella et. al (2005), “não apenas incorporando novas formas de representação do conhecimento, mas também, favorecendo o repensar das práticas docentes, de forma a viabilizar mudanças qualitativas no processo de aprendizagem dos alunos".

O desenvolvimento das TIC constitui um fator-chave para compreender e explicar as transformações econômicas, sociais, políticas e culturais das duas últimas décadas. Para Litwin (1997), apesar desses papéis serem relevantes no atual contexto da escola, é ainda controversa a forma como se dá a apropriação destas tecnologias educacionais no âmbito da educação. Essa questão mantém-se atual e, nos últimos dez anos, apesar de muitos investimentos e inúmeras propostas para informatização das escolas, pouco se avançou quanto à eficácia de projetos e programas que possam ser estendidos simultaneamente a diferentes níveis de ensino.

Para Prandini (2007), “a Internet cria uma nova cultura, que muda os limites entre o público e o privado. Tudo para o universo dos estudantes vira público e vai para (está na) Internet, enquanto o privado praticamente não existe”. De certa forma podemos considerar que o uso da Internet e a maestria de muitos estudantes nesse ramo das comunicações invertem a lógica prevalecente das salas de aula.

Nas escolas essa tendência “moderna” começa a afetar os planos e programas de estudos, direta e indiretamente, positiva e negativamente, através de práticas nem sempre satisfatórias, pois os projetos educativos não estão ainda preparados para essa 
demanda. A inserção de novos comportamentos sociais nas ações escolares requer professores capacitados a lidar com as tendências tecnológicas da nossa sociedade.

No âmbito da utilização das tecnologias no ensino de Ciências ainda há muito a se investigar (Moreira, 2003). É possível destacar como principais potencialidades dos ambientes virtuais a oferta de recursos informáticos de diferentes fontes e formatos, que possibilitam a distribuição e recomendação de materiais didáticos de qualidade, a cooperação, o aprofundamento de conceitos e fenômenos naturais, a oferta de ferramentas de coleta, manipulação e apoio na análise de dados e a possibilidade de interação e troca de experiências por meio das diferentes ferramentas de comunicação.

Considera-se que uma das formas mais promissoras de utilização das TIC na educação é através dos ambientes virtuais de aprendizagem. Estes ambientes, em tese, podem dar mais significado ao ensino, favorecer a motivação e a cooperação entre os estudantes, o que em si, já seria um ganho (Jonassen, 1998).

Jonassen (1998) vê nas tecnologias um importante aliado do professor, pois elas facilitam o ensino e a aprendizagem. Adverte, porém que as tecnologias não podem provocar mudanças por si só, é preciso uma transformação nas concepções e métodos de ensino e aprendizagem. Argumenta que "as abordagens construtivistas, são as que mais contestam o currículo padrão, pois consideram a necessidade do rompimento com a aprendizagem mecânica, que ainda é a tônica da sala de aula".

Enfatiza-se que o potencial educativo das TIC favorece novos enfoques pedagógicos e metodologias a serem considerados no ensino, como as comunicações mediadas por computador, o trabalho cooperativo, a aprendizagem colaborativa, os ambientes de aprendizagem interativos e as ferramentas cognitivas baseadas no computador.

Um ambiente virtual de aprendizagem com características de interatividade consiste de um problema ou espaço de projetos, onde devem estar presentes, fontes de informação, ferramentas cognitivas variadas, situações relacionadas (bons exemplos), ferramentas de colaboração e diálogo, apoio contextual, favorecendo a criação de hábitos educativos, é o que nos faz entender o pesquisador (Jonassen, 1998).

Rezende e Ostermann (2004), tratando da utilização de ambientes virtuais de aprendizagem na formação de professores situam como um plano de ação importante quanto ao desenvolvimento do conhecimento profissional, o estímulo à reflexão sobre a prática, a interatividade e o incentivo à colaboração. Depreende-se que estas 
preocupações são crescentes, sendo uma das mais comuns à integração dos processos educativos formais nas escolas ao uso da Internet e de outros recursos didáticos no formato digital.

Uma das estratégias que pode se articular ao trabalho com os ambientes virtuais de aprendizagem, são as ações que provocam uma tomada de consciência por parte do professor das idéias prévias dos estudantes sobre o que se pretende ensinar. Há um consenso ente os pesquisadores em ensino de Ciências que apontam a identificação das concepções dos estudantes como a principal necessidade quando se ensina Ciência (Moreira, 2006 e Carvalho e Gil-Pérez, 1995).

A Aprendizagem Baseada em Casos, ou simplesmente ABC, é uma metodologia, considerada por Savery e Duffy (1995) como capaz de produzir informações sobre as concepções iniciais dos aprendizes e favorecer a construção de conhecimentos em patamares de complexidade variáveis. Para os autores, quando se aprende não é possível estabelecer limites para aprendizagem, que, portanto não pode ser colocada em um só nível para mais de um indivíduo. Como conseqüências desta observação, reconhecem que quando um professor ensina, na prática está buscando auxiliar o aprendiz a construir conhecimentos próprios que irão variar na medida em que as bases de construção se diferenciam, porém em quaisquer condições a identificação das idéias iniciais dos aprendizes irá sempre favorecer o método de ensino, qualquer que seja ele.

ABC é uma estratégia de ensino desenvolvida com a intenção de colocar o aluno em contato direto com problemas reais da sua profissão futura (Savery e Duffy, 1995). Por se tratar de uma estratégia que favorece o contato com a experiência profissional antes do término da formação difundiu-se rapidamente em diferentes áreas do conhecimento, pois evidencia intervenções agudas, clínicas, motivadoras e geradoras de conflitos. Na área médica, por exemplo, é consenso, já que, “admite-se que existe um tempo para errar, que não é após a formação” (Watson, 1997 p 12).

Para Savery e Duffy (1995), a complexidade de um Estudo de Caso está limitada aos interesses dos professores e estudantes, o que sugere que seja uma boa estratégia para produzir as ligações de conteúdos científicos e significados do cotidiano dos aprendizes, que normalmente ficam faltando nos métodos de ensino mais tradicionais, quando o professor segue um roteiro ou manual.

No âmbito deste trabalho, uma proposta pedagógica foi desenvolvida com apoio das TIC orientada pela metodologia de ABC. O aprofundamento das 
concepções sobre ensino e aprendizagem aliadas ao desenvolvimento tecnológico, orientou a modelagem e desenvolvimento do ambiente virtual de aprendizagem, denominado Espaço Virtual de Aprendizagem, ou simplesmente EVA, cujo modelo conceitual é a estratégia de Estudos de Caso (Reis e Linhares, 2005b) ${ }^{3}$.

O EVA consiste em um ambiente virtual de aprendizagem organizado em torno de situações de ensino que se estruturam de acordo com a metodologia de ABC, complementando-se pela existência de funções de interatividade (chat, fórum, e-mail interno), contém um kit pedagógico (biblioteca de materiais) e outras funcionalidades de gerência e informação.

A proposta pedagógica na Licenciatura em Física tem por característica uma organização do ambiente de aprendizagem em função de Estudos de Caso, que contemplam temas de conteúdos específicos e pedagógicos, articulando teoria e prática. Os Estudos de Caso devem se constituir de problemas ou questões relevantes, a partir das quais os estudantes devem construir o conhecimento, a fim de moldar desempenhos efetivos; as tarefas são réplicas de problemas enfrentados pelos professores na prática docente.

O presente trabalho analisa um Estudo de Caso que versou sobre a importância do currículo como um elemento condutor do processo educativo, capaz de orientar a produção de ações pedagógicas diferenciadas, emancipadoras e reflexivas. A intenção principal é avaliar o que os licenciandos entendem por currículo antes e depois do estudo.

Na consecução deste trabalho coletamos e analisamos os dados relativos ao Estudo de Caso sobre o currículo de Física, as falas dos licenciandos, armazenadas no EVA, quando responderam, expondo suas concepções a respeito do tema currículo no início e no final do Estudo de Caso. Os dois objetivos são avaliar a:

1. Evolução das concepções dos futuros professores de Física sobre as componentes curriculares: conteúdos, metodologias e avaliação, de acordo com o referencial de Porlán e Rivero (1998) e;

2. Eficácia e funcionalidade do ambiente.

\footnotetext{
${ }^{3}$ O EVA pode ser acessado em <www.uenf.t5.com.br $>$
} 


\section{Visão de Currículo}

O Currículo, a forma como contemporaneamente organizamos o conhecimento e o saber com vistas ao seu ensino (Goodson, 2008), está centralmente implicado em um processo de contenção e subjetivação. Para o estudioso desta área:

"Construir um mundo social que não fique sujeito às invenções $e$ convenções do passado e assinalar a contingência de nossos presentes arranjos sociais significa abrir o pensamento e a ação para a invenção de novos e subversivos modos de agir e para formas renovadas e novamente inventadas de organizar a vida e o mundo sociais". (op. cit p.76).

O currículo é um tema do qual divergem conceitos e questões de interesse dos professores, mas, que por se mostrar de alta complexidade permanece distante das salas de aula na maior parte das Licenciaturas (Sacristán, 2000). Um agravante, é que o tempo necessário para debates e leituras é sempre pequeno, o que contribui para que muitos professores se formem sem ter tido a oportunidade de discutir outras concepções sobre currículo diferentes da usual e atual relação de conteúdos.

A noção de currículo pode variar de acordo com a abordagem de cada autor. Sacristán (2000) compreende o currículo como construção cultural, "um modo de organizar uma série de práticas educativas" (p.14). Ressalta que os currículos determinam os fins da educação no ensino escolarizado, pois expressam o equilíbrio de interesses e forças que gravitam sobre o sistema educativo num dado momento. Segundo o autor:

"a perspectiva prática sobre o currículo resgata o como se realiza o fato, o que acontece quando está se desenvolvendo. As condições e a dinâmica da classe, as demais influências de qualquer agente pessoal, material, social, tecnológico etc, impõem ou dão o valor real ao projeto cultural que se pretende como currículo na escola” (Sacristán, 2000, p.51).

Stenhouse (1986) entende o currículo como um aliado do professor para o desenvolvimento da disciplina, um campo onde o professor pode desenvolver novas habilidades, relacionando-as com as concepções do conhecimento e da aprendizagem. "Através de materiais e critérios para realizar o ensino, expressa toda uma visão do que é o conhecimento da disciplina e uma concepção do processo da educação".

Uma perspectiva político-educativa é destacada por Freire e Shor (1987) a partir da compreensão de currículo, que os próprios autores denominam de subversiva: 
"o Currículo padrão lida com a motivação como se esta fosse externa ao ato de estudar. As provas, a disciplina, os castigos, as recompensas, a promessa de emprego futuro são considerados os motores da motivação” (p.15).

Na perspectiva de um desenvolvimento grupal ou coletivo através do estudo das matérias escolares, Goodson (2008) considera que: "os estudos de caso sobre matérias escolares proporcionam o "detalhe local” de mudança e conflito curriculares necessários ao interesse geral” (p.76).

Este estudioso do currículo entende que concentrar a atenção no micronível de grupos ligados a interesses de alguma matéria escolar é valorizar as mudanças econômicas de macronível e as idéias intelectuais, além de valorizar os sistemas e as tecnologias educacionais.

No caso do Ensino Médio no Brasil, os Parâmetros Curriculares Nacionais (Brasil, 1998; Brasil, 2002) são indicadores de posturas curriculares no que diz respeito, não só, aos conteúdos que podem favorecer uma formação qualificada para o trabalho e vida em sociedade, mas define questões no âmbito de habilidades e competências que devem ser desenvolvidas. Portanto, contribuem para a organização de trabalhos e atividades de professores e alunos nas escolas. Nesse sentido, estes documentos apontam para a familiarização e introdução de forma eficiente das tecnologias computacionais nos currículos.

\section{O Conhecimento Profissional do Professores}

Porlán e Rivero (1998) estudaram o conhecimento dos professores de Ciências e identificaram na evolução progressiva desses conhecimentos, elementos que foram utilizados numa proposta formativa para professores dessa área.

Ao adotar a identificação de quatro estruturas como base formadora das ações profissionais dos professores, Porlán e Rivero (1998) nomeiam a progressão do conhecimento profissional como o avanço e reorganização do conhecimento profissional dominante transformado no conhecimento profissional desejável. Nesse processo inserem-se as concepções sobre: Ciência, Ensino, Aprendizagem e Currículo.

Nesse contexto, para Porlán e Rivero (1998) a formação de professores nas áreas de Ciências/Física é baseada no desenvolvimento das idéias, devendo a progressão profissional ser orientada por atividades investigativas que cercam os problemas curriculares. 
No estudo sobre progressão do conhecimento profissional docente, Porlán e Rivero (1998) elaboram uma síntese ampla das análises de outros autores sobre modelos de formação, classificando as tendências existentes, tendo as concepções epistemológicas como destaque. O modelo Tradicional, que privilegia o saber acadêmico em detrimento do conhecimento prático e faz uso massivo de metodologias de ensino que carecem de fundamentação teórica é caracterizada pela reprodução mecânica do conhecimento acadêmico.

O modelo Tecnológico se diferencia do Tradicional por reconhecer a dimensão prática da atividade docente, entretanto também supervaloriza o conhecimento teórico. “O ensino é uma tecnologia constituída de métodos que os professores devem dominar” (Porlán e Rivero, 1998).

O saber fenomenológico é privilegiado no modelo Espontaneísta, que considera o aprendizado como um processo que ocorre de maneira espontânea, sem necessidade de um planejamento específico. "Reconhece apenas o conhecimento prático para a progressão do conhecimento profissional do professor e desconsidera as contribuições teóricas” (Porlán e Rivero, 1998).

Os autores propõem um modelo alternativo aos anteriores definindo o conhecimento profissional desejável, caracterizado por: “um saber acadêmico elaborado, princípios e crenças autônomas e rotinas de ações diversificadas em contraste com o saber acadêmico enciclopédico, princípio e crenças estereotipados, rotinas e guias de ações mecanizadas” (Porlán e Rivero, 1998).

Para alcançar o conhecimento profissional desejável o professor:

"partindo do modelo didático tradicional, deve superar obstáculos através de um processo contínuo de reorganização do conhecimento profissional, passando por etapas (inicial, de transição e final) - os modelos didáticos estão relacionados às concepções de ensino, aprendizagem, ciência, conhecimento escolar, de conteúdos, de metodologia e de avaliação que os professores possuem” (op. cit. p.

Na proposta de Pórlan e Rivero (1998) a formação de professores é baseada no desenvolvimento progressivo das idéias dos professores e, a progressão do conhecimento profissional é guiada por atividades de investigação que estes desenvolvem em torno dos problemas curriculares, que constituem o ponto de encontro entre os conteúdos formativos e as estratégias de formação. Essa proposta 
pretende melhorar os sistemas de idéias pré-existentes, buscando torná-los mais adequados, coerentes e complexos a partir da expressão das concepções dos professores e da consideração de diferentes perspectivas.

O último estágio da formação almejada corresponde a um modelo de ensino construtivista, segundo o qual o perfil profissional é coerente com a idéia do professor investigador que participa de projetos de experimentação curricular e da progressão do conhecimento profissional: "Propõe-se uma visão de mundo alternativa ao paradigma mecanicista e à ideologia dominante, baseada na concepção complexa e relativa da realidade $e$, no planejamento ideológico, crítico inserido numa perspectiva construtivista e evolutiva do conhecimento” (Porlán e Rivero, 1998).

Adotamos neste trabalho estes pressupostos teóricos e guiamos a conduta formadora pelo objetivo de trabalhar a progressão do conhecimento escolar dos licenciandos.

\section{Aprendizagem e Desenvolvimento}

Vygotsky (1984) considera que "não existe melhor maneira de descrever a educação do que considerá-la como a organização de hábitos de conduta e tendências comportamentais adquiridas” (p. 105). Numa abordagem considerada sócio-interacionista este autor valoriza o desenvolvimento através das relações do indivíduo e sociedade, numa forma diferente de entender a educação. Esta concepção de educação favorece o diálogo, tendo como premissa a constituição do indivíduo através de suas interações sociais, alguém que transforma e é transformado nas relações produzidas em uma determinada cultura.

Ao admitir a interação do indivíduo com o meio como característica definidora da constituição humana, Vygotsky (1984) considera que o desenvolvimento não é uma somatória entre fatores inatos e adquiridos e sim uma interação dialética que se dá entre o indivíduo e o meio social e cultural que se insere. Não ignora as definições biológicas do homem, no entanto atribui importância à dimensão social, que fornece instrumentos e símbolos da mediação com o mundo. O aprendizado é considerado um aspecto necessário e fundamental no processo de desenvolvimento de funções psicológicas superiores.

Nessa perspectiva, é o aprendizado que possibilita e movimenta o processo de desenvolvimento “o aprendizado pressupõe uma natureza social específica e um processo através do qual o indivíduo penetra na vida intelectual daqueles que o 
cercam” (op. cit. p. 99). Identifica dois níveis de desenvolvimento: um relativo aos conhecimentos existentes, denominado nível de desenvolvimento real, e outro, o nível de desenvolvimento potencial, que se relaciona aos conhecimentos a serem adquiridos. Para chegar a este nível o indivíduo precisa de outra pessoa (orientador próximo, colegas experientes - diálogo), solucionando determinados problemas através do diálogo, colaboração, imitação, das experiências compartilhadas e pistas que lhes são fornecidas.

É assim, que Vygotsky compreende o desenvolvimento, considerando uma região intermediária e de fronteiras não bem delimitadas, onde seja possível atuar visando facilitar a aprendizagem:

“A distância entre o que é capaz de fazer (aprender) de forma autônoma e o que pode fazer em colaboração com os elementos de seu grupo social (nível de desenvolvimento potencial) caracteriza a zona de desenvolvimento proximal (ZDP). Esta região define funções ainda não amadurecidas, latentes" (op. cit. p. 98).

No favorecimento da aprendizagem, é possível compreender que um dos papéis do professor seja o de parceiro mais capaz, que atua na condução do processo de ensino e orienta a aprendizagem do estudante, por meio de interações sociais adequadamente orientadas.

Ações de ensino e aprendizagem conduzidas a partir de interações podem ser mais potentes, pois já consideram em sua essência, o desenvolvimento como necessário, o principal fator da ampliação e melhoria da qualidade do diálogo e das argumentações. É possível considerar que quando o processo e as estratégias de ensino favorecem o diálogo e a argumentação, ampliam as condições de aprendizagem dos estudantes através, principalmente, da interação.

\section{Desenvolvimento do Estudo de Caso}

No Estudo de Caso analisado neste trabalho indagamos que conhecimentos possuem os licenciandos sobre o conceito de currículo e avaliamos até que ponto os estudantes modificaram suas concepções ao término do estudo. É possível identificar algum avanço na forma como se pronunciam no encerramento do Estudo de Caso? Espera-se que os estudantes sejam capazes após o estudo, de oporem-se às definições mais tradicionais do currículo como programa e guia de aulas. 
O Estudo de Caso, “O Currículo de Física no Ensino Médio: reflexões e contexto” é apresentado em anexo. A leitura indicada para resenha analisa detalhadamente as orientações educacionais complementares aos Parâmetros Curriculares Nacionais - PCN+ (Brasil, 2002), abordando os temas estruturadores do ensino de Física como uma proposta de valorização curricular (Kawamura e Housome, 2003).

O currículo de Física deve ser entendido pelo professor como algo bem mais amplo do que listas de conteúdos de Física. É preciso que ao avaliar os interesses quando ensina, o professor considere as interações sociais e educacionais presentes no ensino (Brasil, 1998). Assim, a complexidade do currículo, permeada politicamente, tecnologicamente, socialmente e educacionalmente deve começar a ser entendida. Nesse sentido, é preciso compreender o currículo como um conceito dinâmico (Goodson, 2008), pois, como fator de intervenção na escola, cobra atualização dos professores e demais membros da comunidade escolar.

Quando trabalham num Estudo de Caso no EVA os estudantes seguem basicamente três passos, que constituem a base da metodologia de ABC: i) o estudante lê o texto do Caso e aponta uma solução preliminar, ii) são encaminhadas leituras e pesquisas sobre o tema; uma leitura é selecionada para ser resenhada, iii) em fase de conclusão o estudante encaminha sua proposta de solução, que deve incorporar elementos das leituras e discussões (Reis e Linhares, 2005a).

\section{Metodologia}

A pesquisa é considerada qualitativa, na medida em que o principal instrumento de coleta de dados, que é o próprio ambiente virtual de aprendizagem, permite analisar o conteúdo presente nas falas dos sujeitos. Considera-se que os pesquisadores conduzem o processo de ensino e o influenciam, ao atuarem diretamente com os estudantes através do EVA. Essa característica situa as atividades que desenvolvemos no âmbito da Pesquisa-Ação..

No estudo “O Currículo de Física: contexto e reflexões” em anexo, 14 alunos da Licenciatura em Física do $6^{\circ}$ período participaram na busca de soluções para a questão: O que você compreende por Currículo? Esse estudo focaliza uma situação real, em que professores se envolveram visando à reformulação do currículo de Física em uma escola. 
Os dados da pesquisa foram obtidos a partir das soluções encaminhadas pelos estudantes nos passos inicial (1) e final (3) do Estudo de Caso, quando emitiram suas respostas sobre o que compreendem por currículo. No primeiro passo o estudante responde as perguntas do Estudo de Caso imediatamente após uma primeira leitura, deixando registrada sua concepção inicial sobre o tema abordado.

Após a leitura do texto "A Contribuição da Física para um Novo Ensino Médio” (Kawamura e Housome, 2003), que deve ser resenhado e registrado no segundo passo e das discussões em sala de aula com o professor e com os colegas, cada estudante deve apresentar uma nova solução para o estudo. Esta última solução pode ser confrontada com a primeira e, isto é feito, no intuito de avaliarmos se a forma de se manifestar em relação ao conceito estudado avançou.

Uma forma de avaliar a criação em textos que advém de questões abertas é a análise de conteúdo (Bardin, 1994). Nesta ferramenta os registros são analisados com o objetivo de revelar as variações da fala em relação a um determinado contexto que deve ser identificado. A análise de conteúdo é feita em relação ao que se compreende das falas dos licenciandos sobre uma construção de conhecimentos do currículo. Identificam-se termos e expressões que podem conduzir o pesquisador a uma avaliação sobre o conteúdo submetido à análise.

Na primeira fase da análise dos dados preenchemos uma planilha para cada estudante. Foi feita uma leitura dos passos iniciais (1) de todos os estudantes e a seguir, dos passos finais (3), dos mesmos estudantes. Foi possível, de acordo com os objetivos do estudo, identificar unidades de significação (valores, atitudes, visões, vivências e opiniões) objetivando uma categorização (Bardin, 1994).

No passo intermediário (2), em que cada aluno apresentou sua resenha foi possível identificar dificuldades em produzir comentários sobre o texto. Por isso, apesar de considerarmos este passo relevante para a apresentação de uma proposta de solução, optamos por não utilizá-lo na análise de conteúdos.

Das “falas” dos estudantes registradas foram criadas categorias relacionadas ao tema de estudo, de acordo com as preocupações dos estudantes com diversos aspectos das ações docentes nas escolas. As categorias foram confrontadas com o modelo de Porlán e Rivero (1998) sobre o conhecimento escolar dos professores de Ciências, com o objetivo de avaliar a progressão dos conhecimentos dos futuros professores sobre elementos que compõem o currículo. 
Na segunda fase da análise elaboramos uma única planilha com a síntese das análises individuais. Reunimos os dados em uma única planilha, objetivando a identificação de certos tipos ou modelos de comportamento emocionais, tais como falas sobre experiências próprias, oposições às leituras, antagonismos em relação a propostas transformadoras, ou simplesmente um consentimento indiferente ao estudo, posições mais ou menos inconscientes, relativamente ao objeto currículo de Física (Bardin, 1994).

\section{Resultados e Análise}

Agrupamos os temas extraídos dos discursos a partir de significados, de acordo com as seguintes categorias: "Preocupação com o Ensino", "Preocupação com o Conteúdo”, "Preocupação com a Metodologia”, "Preocupação com a Avaliação”, "Preocupação com o Currículo", "Vivências e Descrença”. As categorias se explicitam através da exposição de significados que surgem na fala dos estudantes em cruzamento com os elementos do conhecimento escolar dos professores de Ciências proposto por Porlán e Rivero (19980, exceção da categoria “vivências e descrença” construída a partir dos significados relevantes contidos nas falas dos licenciandos, que ajudam na compreensão de suas dificuldades.. Cada uma das categorias pode ser identificada por uma série de atitudes relatadas, como descrevemos a seguir:

A categoria "Preocupação com o Ensino" denota um conjunto de significados manifestos nas soluções apresentadas, em que sobressai o receio de não saber ensinar. Prevalece a tendência em compreender a prática docente como "transmissão" de conteúdos. Nesta categoria também estão presentes as manifestações de preocupação com a aprendizagem.

A categoria "Preocupação com o Conteúdo" evidencia o que os estudantes aprenderam a reconhecer como uma seqüência lógica de conteúdos, o receio desta seqüência não ser ministrada e a falta de condição para trabalhar conteúdos novos e outros, não trabalhados com regularidade. Apresenta também a preocupação em atender os aportes atuais sobre a necessidade de se estudar a ciência do dia-a-dia, traduz de certa forma, a dependência ao livro didático.

A categoria "Preocupação com a Metodologia” expõe uma parte dos “medos” que são encontrados nas visões de Freire e Shor (1987) sobre o cotidiano da sala de aula e da profissão docente. É possível reconhecer nas falas o entendimento da 
necessidade de transformar o que se denomina "modelo tradicional de ensino", mas teme-se não estar preparado para tal.

A categoria "Preocupação com a Avaliação" expõe as dúvidas sobre como verificar se o aluno está aprendendo ou não. Num contexto mais amplo os estudantes têm dificuldades em se referir a esta categoria de forma explícita, porém demonstram suas próprias preocupações com o "passar de ano”, “ser aprovado na cadeira”, que ainda manifestam enquanto alunos na Licenciatura.

A categoria “Preocupação com o Currículo” manifesta a própria dificuldade de realização deste Estudo de Caso e é claramente perceptível quando os estudantes se referem ao "programa de Física no ensino médio”, ao “vestibular” e a necessidade de “cumprir a risca o que foi determinado”. A necessidade dos estudantes terem um livro texto que ajude o professor a ensinar “tudo” que “precisa” ser ensinado.

A categoria "Vivências e Descrença" identifica-se quando os estudantes mostram-se descontentes com a forma como estudam e provavelmente irão trabalhar (projeção de um futuro ameaçador). Nesse caso, é comum manifestarem descrença quanto à transformação da prática profissional. Incluem-se as dificuldades inerentes como à preocupação já existente com as múltiplas jornadas, o pouco tempo para continuar aprendendo, o desleixo dos alunos no ensino médio, a indisciplina etc. É possível verificar-se comparações com a forma como estudaram no ensino médio e na graduação.

Na síntese da análise de conteúdo das “falas” dos estudantes da Licenciatura foi possível elaborarmos a planilha apresentada no quadro 1. Este instrumento organiza os resultados encontrados durante a realização do Estudo de Caso.

Quadro 1: Categorias extraídas das falas dos licenciandos em Física.

\begin{tabular}{|c|c|c|}
\hline & \multicolumn{2}{|c|}{$\begin{array}{c}\text { OBJETO } \\
\text { DE CATEGORIZAÇÃO }\end{array}$} \\
\hline \begin{tabular}{|l|} 
TIPO \\
DE \\
RELAÇÃO
\end{tabular} & $\begin{array}{c}\text { Passo 1: } \\
\text { Proposta de solução inicial }\end{array}$ & $\begin{array}{c}\text { Passo 3: } \\
\text { Proposta de solução final }\end{array}$ \\
\hline $\begin{array}{l}\text { Preocupação } \\
\text { com o } \\
\text { Ensino }\end{array}$ & $\begin{array}{l}\text { Interdisciplinaridade, - o que é ciência?, } \\
\text { aprendizagem, interesse, investigação, } \\
\text { professor ensina X aluno aprende, curiosidade, } \\
\text { frustração e medo, física do cotidiano, decorar } \\
\text { X compreender, "passar” o básico, pesquisar é } \\
\text { difícil. }\end{array}$ & $\begin{array}{l}\text { Avanço conceitual, motivação, reflexão, } \\
\text { aprendizagem, competência/habilidades, } \\
\text { interdisciplinaridade, contextualização, o } \\
\text { sócio-cultural, professor transmissor não, } \\
\text { PCN e profissionalização, conceitos, } \\
\text { cotidiano, aprendizagem do professor, } \\
\text { Física Moderna, estratégias de ensino. }\end{array}$ \\
\hline
\end{tabular}

\footnotetext{
${ }^{4}$ Consideramos que a visão que compartilhamos com os estudantes sobre o que se chama modelo tradicional de ensino diz respeito à extrema valorização da memorização nas aulas de Física, o uso massivo de provas direcionadas para conteúdos, em que prevalecem os aspectos matemáticos. Ausência de estratégias de ensino inovadoras.
} 


\begin{tabular}{|c|c|c|}
\hline $\begin{array}{l}\text { Preocupação } \\
\text { com o } \\
\text { Conteúdo }\end{array}$ & $\begin{array}{l}\text { Dificuldades com a matemática, conceitos, } \\
\text { história da Ciência, cinemática no início, que } \\
\text { conteúdos ensinar?, realidade, novos } \\
\text { conteúdos, Física Moderna (SIM), Física } \\
\text { Moderna (NÃO), mudanças nos conteúdos } \\
\text { ensinados, formalismo matemático menos, } \\
\text { aspectos sociais. }\end{array}$ & 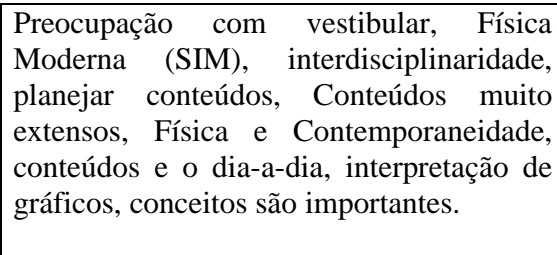 \\
\hline $\begin{array}{l}\text { Preocupação } \\
\text { com a } \\
\text { Metodologia }\end{array}$ & $\begin{array}{l}\text { Matemática é ferramenta, relatos criativos, } \\
\text { aulas de leitura, Laboratórios didáticos, vídeos, } \\
\text { diálogos, métodos tradicional não, } \\
\text { construtivismo investigativo, computador, } \\
\text { transmissão = decorar (NÃO), terrorismo dos } \\
\text { cálculos, - que métodos usar?, manter aulas } \\
\text { tradicionais, professores devem cooperar, } \\
\text { experiências. }\end{array}$ & $\begin{array}{l}\text { Reciclar professores, melhorar aulas, aulas } \\
\text { dinâmicas e lúdicas, propostas novas e } \\
\text { metodologias focadas no cotidiano, PCN, } \\
\text { livros e pesquisas, novos materiais } \\
\text { didáticos, construtivismo, transmissão não, } \\
\text { estudos de caso, leitura, exemplos, } \\
\text { investigação, usar tecnologias, diálogo, } \\
\text { conservadorismo arraigado prejudica. }\end{array}$ \\
\hline $\begin{array}{l}\text { Preocupação } \\
\text { com a } \\
\text { Avaliação }\end{array}$ & $\begin{array}{l}\text { Provas somente não, avaliação tradicional X } \\
\text { avaliação processual, ênfase deve ser na } \\
\text { aprendizagem, - como avaliar? Deve usar as } \\
\text { provas tradicionais sim. }\end{array}$ & $\begin{array}{l}\text { Avaliações com foco na aprendizagem, } \\
\text { material didático elaborado com o aluno, } \\
\text { avaliar idéias dos alunos, avaliação } \\
\text { contínua, qualidade, re-elaboração. }\end{array}$ \\
\hline $\begin{array}{l}\text { Preocupação } \\
\text { com o } \\
\text { Currículo }\end{array}$ & $\begin{array}{l}\text { Reforma curricular, currículo maçante, } \\
\text { currículo desatualizado, currículo inviável, } \\
\text { currículo amplo, currículo = programa, grade } \\
\text { curricular, facilitar o trabalho do professor, } \\
\text { vestibular é importante e o foco. É preciso } \\
\text { ensinar tudo que se precisa. }\end{array}$ & $\begin{array}{l}\text { Reforma curricular, PCN e PCN+, } \\
\text { reavaliar "grade", currículo ultrapassado, } \\
\text { currículo e realidade, Física no ensino } \\
\text { fundamental, Física mais Matemática } \\
\text { juntas, competências e habilidades, acesso } \\
\text { ao conhecimento amplo, compreensão de } \\
\text { códigos, currículo é fragmentado, } \\
\text { organizar disciplinas, - o que é o currículo } \\
\text { do ensino médio? Currículo extenso, - o } \\
\text { que é currículo? Os temas estruturadores, } \\
\text { realidade das escolas deve pesar, } \\
\text { conteúdos X vestibular. }\end{array}$ \\
\hline $\begin{array}{l}\text { Vivência } \\
\text { e } \\
\text { Descrença }\end{array}$ & $\begin{array}{l}\text { Prof. de física X de matemática, falta de tempo } \\
\text { para o programa, resistência dos professores, a } \\
\text { realidade é distante, prof. precisam trabalhar } \\
\text { muito, prof. não gostam de cooperar entre si, } \\
\text { prof. não se adaptam à metodologias } \\
\text { inovadoras, alunos têm dificuldades de } \\
\text { aprendizagem. Medo da matéria, o número } \\
\text { reduzido de aulas de física, a ciência já vem } \\
\text { pronta, vivência de um ensino decepcionante, } \\
\text { baixos salários dos professores atrapalham. } \\
\end{array}$ & $\begin{array}{l}\text { Lentidão na tomada de decisão nas } \\
\text { escolas, práticas escolares são arraigadas, } \\
\text { inadaptação às propostas inovadoras, } \\
\text { ignora os PCN, no atual momento da } \\
\text { escola pública é inviável qualquer ação } \\
\text { modificadora, alunos não aprendem } \\
\text { mesmo, escolas não aceitam mudanças e } \\
\text { inovações. Desatualização do professor, } \\
\text { autonomia do professor na escola é } \\
\text { reduzida, temer mudanças. }\end{array}$ \\
\hline
\end{tabular}

Ao confrontarmos os dados analisados com o referencial sobre a progressão dos conhecimentos profissionais dos professores de Ciências é possível compreender que os estudantes estão conscientes quanto à existência de situações problemáticas, críticas e emblemáticas relacionadas ao ensino de Ciências (Porlán e Rivero, 1998). Entretanto, consideram o currículo como uma relação de conteúdos que pouco tem a ver com a visão de currículo como um instrumento de organização da escola, da sala de aula e das ações profissionais do professor (Stenhause, 1986 e Sacristán 2000).

Sobre o avanço conceitual, tomando-se como base um discurso médio, fica claro que a coluna relativa ao terceiro passo é mais densa, impregnada das leituras, mais controversa, o que nos parece interessante sob o aspecto de que, aprender neste caso, significa também se questionar. 
Na primeira linha do quadro 1, que destaca as "Preocupações com o Ensino" vemos que os estudantes começam a refletir sobre aprendizagem e demonstram identidade com diferentes elementos relacionados ao ensino. Dentre estes elementos, destaca-se a concepção inicial do professor como transmissor de conhecimento e do aluno como aprendente, contrapondo a visão final de "professor transmissor não". Nesse sentido, apontam como relevante a aprendizagem do professor.

O que pensam sobre o conteúdo de Física, o que irão ensinar em salas de aula e o que estão aprendendo é um conflito que presenciamos no dia-a-dia. Os estudantes sabem o que é recomendado pelos programas nas escolas, pois conviveram com estas determinações até pouco tempo como alunos no Ensino Médio, porém os estudos que fazem na graduação não são suficientes para lhes dar segurança em relação ao que deverão ensinar.

Mudanças são questões polêmicas e transparecem, quando, por exemplo, se discute a inclusão de Física Moderna e Contemporânea no currículo. Outros conteúdos menos aprofundados na graduação e o formalismo matemático são também alvos de preocupações, o maior é o vestibular ao final do Ensino Médio. Este é considerado como um impedimento para adoção de um programa diferenciado, como a própria inserção da Física Moderna e a interdisciplinaridade.

Decorrente da preocupação com o conteúdo se estabelece a preocupação com a metodologia e aí, é possível ver que o método tradicional de ensino é combatido, porém as sugestões de uso de experiências, vídeos, computadores e outras abordagens denominadas “construtivistas” não são clarificadas. Destaque-se na visão final o interesse pelos livros e pesquisas escolares que podem favorecer um ensino de natureza construtivista.

A avaliação foi pouco percebida como um elemento inerente ao currículo. Inicialmente fica evidente a contraposição entre avaliação tradicional (provas) e avaliação processual: “como avaliar?”. Como solução final a importância dada a tomada de concepções iniciais dos alunos e uma avaliação contínua são citadas, de forma superficial. Como esta é uma questão de alta complexidade, não é intenção desse estudo seu aprofundamento. Não obstante, também transparece a visão de Freire e Shor (1987) sobre o fato de "provas e recompensas serem considerados como elementos motivacionais da aprendizagem”.

Quanto à preocupação com o currículo, a visão inicial que prevalece é do currículo apenas como o programa de Física, uma relação de conteúdos que visa 
atender os interesses do vestibular. No passo final percebe-se as marcas das leituras efetuadas, os PCN e a questão da reforma curricular são destacados. Entretanto, falta amadurecimento sobre as novas idéias e o entendimento do currículo como um "programa extenso" ainda convive com os novos conhecimentos que vão se construindo. Consideramos que os estudantes avançaram conceitualmente até onde suas condições de concentrarem-se no estudo, capacidade de leitura e pesquisa escolar permitiram.

Na categoria "Descrenças e Vivências" expõe-se uma grave marca que os futuros professores levam para o início das ações profissionais. Fica explícita a consideração aludida por Freire e Shor (1987) sobre “o medo que ronda a cabeça dos professores quando ele dá aula”: “falta tempo para o programa”, “a realidade é distante” e outras. No passo final percebe-se uma consciência quanto a falta de aproximação de propostas inovadoras, utilização e conhecimentos dos PCN, desatualização do professor e outros.

O sentimento de descrença pode ser ilustrado quando um dos estudantes expõe o seguinte sentimento em relação à aprendizagem de Física: “...não adianta, pois os alunos não aprendem mesmo”. Além disso, alguns licenciandos que já atuam como professores de Física mostram-se menos preparados para discutir a questão currículo, pois apresentam uma postura de conformismo com o quadro precário do ensino de Física que vivenciamos na região. No entanto, consideramos estas manifestações naturais no momento atual da escola, pois fazem parte do cotidiano dos pais de alunos, dos estudantes e também dos professores, que têm visões diferenciadas e muitas vezes antagônicas sobre o ensino e a aprendizagem. Este é um dos aspectos que precisamos compreender melhor se queremos avançar no sentido de uma formação de professores de Física mais qualificada.

Ao valorizar suas vivências os licenciandos mostram o quanto é difícil mudar de postura e isso ratifica a importância de uma formação continuada que precisa ser iniciada tão logo a graduação seja concluída. Sem apoio, a tendência é a retomada das concepções sobre ensino que os futuros professores vivenciaram na maior parte de suas vidas escolares.

Como este Estudo de Caso foi aplicado na fase inicial da disciplina não se obteve um conjunto de significados suficiente para identificarmos uma forma progressiva de conceituação do conceito de currículo. Como apontam Freire e Shor (1987) fica uma visão de currículo (programa) padrão que vem de fora. 
Contrariamente à Stenhouse (1986) não se manifesta a compreensão do currículo ser “valioso como expressão de uma visão do que é o conhecimento da disciplina e uma concepção do processo educativo".

Considerando a conceituação de Sacristán (2000): “os currículos são a expressão do equilíbrio de interesses e forças que gravitam sobre o sistema educativo num dado momento, enquanto que através deles se realizam os fins da educação no ensino escolarizado", não foi identificado um entendimento do conceito desta forma, em se tratando de confrontar com a prática nas escolas, mesmo se levarmos em consideração que alguns estudantes já exercem regularmente a docência.

Entendemos que o trabalho realizado contribuiu para instrumentalizar os estudantes para suas futuras práticas docentes como professores de Física, e principalmente para os próximos Estudos de Caso na disciplina Estratégia para o Ensino de Física.

As concepções finais do grupo de licenciando sobre o Estudo de Caso foram confrontadas com o modelo do conhecimento escolar dos professores de Ciências proposto por Porlán e Rivero (1998). Como resultado, verificamos que o grupo encontra-se em um nível intermediário caracterizado em alguns momentos pelo modelo de ensino tecnológico e em outros momentos pelo espontaneísta. O conhecimento escolar é concebido como produto acabado e processo técnico ou um produto aberto gerado pela desatenção em relação às teorias educacionais.

As visões de aprendizagem predominantes estão relacionadas à assimilação de significados acadêmicos e apropriação espontânea de significados do cotidiano.

O entendimento dos conteúdos curriculares é manifestado como versão adaptada dos conteúdos científicos ou baseado nas experiências e interesse dos alunos.

As visões prevalecentes de metodologia são de seqüência indutiva e fechada de atividades práticas ou atividades pouco sistemáticas, organizadas e baseadas em experiências.

Quanto à avaliação, o grupo expõe a concepção de avaliação objetiva, embora surjam expressões diferenciadas, como “contínua” e “avaliar idéias dos alunos”. 


\section{Considerações Finais}

O estudo do currículo mostrou-se relevante quanto à intenção de propiciar uma formação do professor de Física mais identificada com a pesquisa, a reflexão e a capacidade de produzir e gerenciar situações de aprendizagem logo no início da disciplina Estratégias para o Ensino de Física.

Os resultados quando comparados com os obtidos por Porlán e Rivero (1998) denotam, em relação às teorias do conhecimento escolar, que o grupo de licenciandos evoluiu de uma posição inicial, do modelo tradicional de ensino para uma posição final identificada com os modelos, Tecnológico e Espontaneísta. De acordo com Porlán e Rivero (1998) o conhecimento escolar desejável dos professores de Ciências é identificado por concepções: de ensino investigativo de aprendizagem como construção de significados de conteúdos como integração e reelaboração de conhecimentos de avaliação processual. Embora esta meta não tenha sido alcançada é ela que orienta as ações da proposta pedagógica da disciplina Estratégias para o Ensino de Física.

Quanto à eficácia e funcionalidade do EVA podemos considerar a ferramenta assíncrona permite que o professor responda cada aluno individualmente, pois as questões complexas não admitem respostas simplificadas. Também é um sistema que pode vir a funcionar com os estudantes no Ensino Médio e desta forma estaremos dando um exemplo e propiciando vivência no uso desta tecnologia aos futuros professores.

O EVA pode ser considerado como uma ferramenta cognitiva que possibilita o desenvolvimento de funções latentes, ainda não amadurecidas no aprendiz (Vygotsky, 1984). A seqüência dos passos de ABC (expõe idéias / concepções prévias - estuda e interage, lê e critica - apresenta e defende uma solução) possibilita um trabalho que favorece atingir o conhecimento desejável.

É importante dispor de uma ferramenta que permita personalizar as atividades atribuídas aos estudantes nos cursos de formação de professores de Física, respeitando o ritmo e interesse individual, aliada à capacidade de acompanhar sistematicamente o processo de resolução de problemas, leva a um salto qualitativo do ponto de vista da didática e da formação profissional. Também as questões de conteúdo da Física, que regularmente se inclui nas programações do Ensino Médio, podem ser trabalhadas com os futuros professores, buscando-se alternativas para o ensino tradicional, que normalmente, é o que os professores assumem quando chegam às escolas. 
A contribuição maior deste Estudo de Caso é que os licenciandos que até então não haviam refletido e estudado sobre o tema currículo de forma ampla e conceitual, passaram a compreender que existem desdobramentos e que as dimensões curriculares, ensino, aprendizagem, conteúdos, metodologia e avaliação influenciam fortemente o trabalho do professor.

\section{Referências Bibliográficas}

Bardin, L. (1994). Análise de Conteúdo. Edições 70. Lisboa.

Brasil. (1998). PCN+ Ensino Médio. Orientações educacionais complementares aos PCN. Brasília: MEC/SETEC.

Brasil. (2002). PCN+ Ensino Médio. Orientações educacionais complementares aos Parâmetros Curriculares Nacionais. Brasília: MEC/SETEC.

Carvalho, A. M. P. de. e Gil-Pérez, D. (1995). Formação de Professores de Ciências: tendências e inovações, $2^{\mathrm{a}}$ edição, série Questões de Nossa Época. Cortez, São Paulo, 120p.

Freire, P. e Shor, I. (1987). Medo e Ousadia: o cotidiano do professor. São Paulo, tradução Adriana Lopez, Rio de Janeiro: Paz e Terra. 224p.

Giamella, T. R., Struchiner, M; Ramos, V. e Lent, R. Pesquisa e Desenvolvimento de um Banco Virtual de Objetos de Aprendizagem em Neurociência. V Encontro Nacional de Pesquisa em Educação em Ciências. Caderno de Resumos, v. 5, Roberto Nardi (org.) Bauru, ABRAPEC, 2005, 519p.

Goodson, I. F. (2008). Currículo: Teoria e História. $8^{a}$ ed. Ed. Vozes, RJ. Petrópolis, 140p.

Jonassen, D. (1998). Designing constructivist learning enviroments. In: Reigeluth, C. M. (Ed) Instructional theories and models. 2.ed. Mashwah:Lawrence Erlbaun.

Kawamura, M.R.D. e Housoume, Y. (2003). A Contribuição da Física para um Novo Ensino Médio. In: Física na Escola. v.4, n.2, São Paulo.

Lehrer, R. (1993). Authors of Knowledge: pattern of hypermedia design. In: Lajoie, S.P., Litwin, E. (1997) Derry, S.J. (eds.) Computers as cognitive tools. Hillsdale (NJ): Lawrence Erlbaum.

Moreira, M. A. (2006). A Teoria da Aprendizagem Significativa e sua

Implementação em Sala de Aula. Editora Universidade de Brasília. 2006. 186p. 
Moreira, M. A. (2003). Pesquisa Básica em Educação em Ciências: uma visão pessoal. Disponível: http://www.unb.br/ppgec/pesbased.pdf. Acesso: 18 julho 2007. Porlán, R. e Rivero, A. (1998). El Conocimiento de los Profesores. Díada, Sevilla. 128p.

Prandini, R. C. (2007). Ataque Virtual. In: Educação. Ano 11, n. 121. p 66-70. Disponível em: <http://www.revistaeducação.com.br> Acesso em: 21 maio 2007. Reis, E. M. (2008). Limites e Possibilidades da Utilização de um Espaço Virtual de Aprendizagem no Ensino e na Formação de Professores de Física. Tese submetida ao Programa de Pós-Graduação em Ciências Naturais da UENF, janeiro. 339p.

Reis, E. M. e Linhares, M. P. (2005a). Discutindo a Ortodoxia do Currículo de Física em um Ambiente Virtual para Estudos de Ciências. XVI Simpósio Nacional de Ensino de Física, In: Anais do XVI Simpósio Nacional de Ensino de Física. Rio de Janeiro, 24 a 28/janeiro.

Reis, E. M., Linhares, M. P. (2005b). Convergências Tecnológicas: redesenhando as fronteiras da formação de professores de ciências. In: V Encontro de Pesquisa em Educação em Ciências, Bauru, Anais do V ENPEC, CD-ROM.

Rezende, F. E Ostermann, F. (2004). Formação de Professores de Física no Ambiente de Virtual Interage: Um Exemplo voltado para a Introdução da FMC no Ensino Médio. Fisica na Escola, v.5, n.2, p 15-19.

Sacristán, J. G. (2000). O Currículo: uma reflexão sobre a prática. Trad. Ernani F. da F. Rosa. 3a. edição, ArtMed. Porto Alegre.

Savery, J. R. \& Duffy, T. M. (1995). Problem Based Learning: An Instructional Model and Its Constructivist Framework Educational Technology. SeptemberOctober, p. 31-37.

Stenhouse Lawrence. (1986). El legado del movimiento curricular. En: Galton, M. Y Moon, b. Cambiar la escuela, cambiar el curriculum. Barcelona. Martínez Roca. Watson, I. (1997). Applying Case-Based Reasoning: tecniques for enterprise systems. San Francisco: Morgan Kaufmann. 128p.

Vygotsky, L. S. (1984). A Formação Social da Mente: o desenvolvimento dos processos psicológicos superiores. Martins Fontes Editora. São Paulo. 191p. 


\section{Anexo}

Texto do Estudo de Caso sobre o Currículo de Física

\section{Currículo de Física: reflexões e contexto}

Em uma escola do ensino médio, que também conta com cursos de graduação, o coordenador da disciplina de Física buscou reunir os professores de ensino médio propondo uma análise do currículo existente, que quanto ao programa de Física para as três séries acompanha a ordem e o conteúdo que se vem trabalhando há mais ou menos trinta anos, presente em boa parte doa livros didáticos.

O coordenador busca, a partir da reflexão com os quinze professores envolvidos, levantar pontos que conduzam a uma proposta concreta de reformulação, ou manutenção desse instrumento de organização da escola que ajuda a concretizar os fins da educação no ensino escolarizado.

O professor Nestor pede a fala e apresenta uma proposta de programa que tem encaminhado junto à suas turmas em nível experimental há pelo menos cinco anos, que considera de bons resultados e que, como afirma, tem contribuído para a formação de um olhar mais crítico sobre a Ciência e em especial a Física por parte dos alunos.

Essa proposta está baseada em uma mudança de metodologia, fundamentada na substituição das avaliações tradicionais no formato de provas por avaliações processuais, onde a ênfase é o avanço conceitual de cada estudante, no emprego de inovações tecnológicas como o uso do computador, softwares educativos e o uso da Internet com ênfase no trabalho cooperativo.

Como expõe ao grupo de professores tem sentido mais interesse dos alunos, se sentido mais motivado para o trabalho e compreende que a experiência didática precisa ser levada para outras salas de aula, pois considera este espaço como o melhor Laboratório para a produção de novos conhecimentos sobre o ensino e aprendizagem de Física.

O professor apresenta uma síntese da programação que elaborou para poder trabalhar com a metodologia de aprendizagem baseada em casos, propõe modificações, excluindo alguns tópicos de conteúdo e incluindo outros, buscando uma nova organização, porém ressaltando a necessidade da mudança metodológica. Visando discutir um dos principais problemas, que tem sido o distanciamento e, em alguns casos embates, entre os professores de Física e Matemática, sugere que alguns professores acompanhem suas atividades nas turmas, além da formação de um ou mais grupos de estudos interdisciplinares com a função de avaliação da experiência didática. Assim, entende que os professores de física e matemática possam trabalhar mais próximos.

Se você faz parte dessa reunião de professores, quais são os pontos que acha interessante levantar?

Você concorda com uma proposta de reelaboração do programa, que digamos de passagem, está presente na maior parte das escolas de ensino médio na região?

Que proposta (s) você faz?

Inicialmente, vamos começar este estudo explicitando uma resposta para a seguinte pergunta:

O que você compreende por Currículo? 